Check for updates

Cite this: RSC Adv., 2018, 8, 41633

\title{
Degradation of chemical warfare agents over cotton fabric functionalized with UiO-66- $\mathrm{NH}_{2} \dagger$
}

\author{
Min-Kun Kim,\$ Sung Hun Kim,\$ Myungkyu Park, Sam Gon Ryu* \\ and Hyunsook Jung $(\mathbb{D}$ *
}

Herein, cotton fabric was treated with an alkaline solution to increase the content of surface hydroxyl groups and then functionalized with $\mathrm{UiO}-66-\mathrm{NH}_{2}$, a nanoporous metal-organic framework. Instrumental analysis of the thus treated fabric revealed that its surface was covered with $\mathrm{UiO}-66-\mathrm{NH}_{2}$ crystals in a uniform manner. The ability of the functionalized fabric to degrade two chemical warfare agents (soman and sulfur mustard) was probed by testing its permeability to these two agents (swatch testing), and the excellent degradation performance was concluded to be well suited for a broad range of filtration and decontamination applications.

Received 14th August 2018

Accepted 5th December 2018

DOI: $10.1039 / \mathrm{c} 8 \mathrm{ra0} 0805 \mathrm{~d}$

rsc.li/rsc-advances

MOFs are organic-inorganic complexes exhibiting a porous

\section{Introduction}

The degradation of chemical warfare agents (CWAs) has drawn increased research attention since their first mass use during World War I, particularly after the recent acts of chemical terrorism. ${ }^{1,2}$ Broadly speaking, CWAs can be classified into nerve agents, which inflict damage to the nervous system, ${ }^{3}$ and blister agents, which cause the appearance of blisters on the victim's skin. The active component of equipment commonly used for protection from agents of both types mainly corresponds to activated carbon, which is characterized by high specific surface area and variable pore $\operatorname{size}^{4}$ and therefore can effectively adsorb various chemicals. However, despite the above advantages, activated carbon can adsorb only limited amounts of CWAs, i.e., large amounts of active materials are required to provide longer lasting protection. Therefore, new methods of achieving lightweight protection, increased operation time, and enhanced CWA degradation activity are highly sought after.,

Recent reports reveal that CWAs can be efficiently decomposed over metal-containing materials such as metal nanoparticles, metal oxides, and inorganic-organic complexes. ${ }^{7-10}$ For instance, $\mathrm{Zr}(\mathrm{OH})_{4}$ is believed to efficiently catalyze the decomposition of CWAs ${ }^{11-13}$ and toxic industrial chemicals. ${ }^{\text {14,15 }}$ Furthermore, the adsorption-based removal of CWAs can be realized using a large number of catalytically active porous materials such as porous organic polymers, zeolites, ${ }^{\mathbf{1 6}}$ polyoxometalates, ${ }^{17-19}$ and metal-organic frameworks (MOFs). ${ }^{20-24}$

Agency for Defense Development, Yuseong, P. O. Box 35-5, Daejeon 34186, Republic of Korea.E-mail: junghs@add.re.kr; sgryu@add.re.kr

$\uparrow$ Electronic supplementary information (ESI) available. See DOI: 10.1039/c8ra06805d

\$ These authors contributed equally to this work. crystalline structure that originates from the combination of a metal cluster and secondary building units bearing organic linkers with one or more benzene rings. ${ }^{25-27}$ To date, MOFs have found numerous applications in the fields of adsorption, ${ }^{28-30}$ catalysis, ${ }^{31}$ air pollution control, ${ }^{32}$ and CWA decomposition. ${ }^{20-24}$

The recently discovered Zr-based MOFs are important examples of this class of porous materials, exhibiting excellent thermal and chemical stability as well as superior CWA adsorption and decomposition performance, with particularly high nerve agent and simulant decomposition efficiencies observed for materials such as UiO-66 and UiO-66- $\mathrm{NH}_{2} \cdot{ }^{33-35}$ Moreover, MOF-808 (featuring clusters with six-foldcoordinated $\mathrm{Zr}$ centers) and NU-1000 (featuring clusters with eight-fold-coordinated $\mathrm{Zr}$ centers) are also known to adsorb and decompose nerve agents and simulants at very high rates. ${ }^{22,33}$ Recently, we have reported that MOF-808 maintains its solidstate crystallinity and excellent nerve agent decomposition ability even in water. ${ }^{36}$

However, to be practically applicable (i.e., in protective clothing), the above materials need to be hybridized with fabrics, which can be achieved by a plethora of methods such as atomic layer deposition (ALD) ${ }^{37}$ electrospinning, ${ }^{38}$ and polymer surface functionalization. ${ }^{39,40}$ However, all of these methods require the use of complicated processes and cannot be easily scaled up.

Herein, we modified the surface of cotton fabric by a simple method known as mercerization to make it better suited for MOF growth, as has been reported elsewhere. ${ }^{\mathbf{4 1 , 4 2}}$

Cotton surfaces are hard to modify in view of the fact that their main constituent, cellulose, comprises hydroxyl groups linked by hydrogen bonds. However, the dyeability/dye adsorption rate, hygroscopicity, and mechanical durability of these surfaces can be improved by a process known as 
mercerization, which is widely used in dye processing. The above process destroys approximately $25 \%$ of hydrogen bonds in the cellulosic fabric and thus increases the content of free hydroxyl groups, changes the crystallinity of cellulose, ${ }^{43}$ and increases the fraction of functional groups inducing the nucleation of particles. The above effects originate from the incorporation of $\mathrm{Na}^{+}$ions between fibers, which increases the proportion of free hydroxyl groups and the amount of space between fibers, therefore allowing for better fiber-precursor contact. Specifically, mercerization reduces the crystallinity of cellulose fibers and increases the fraction of the amorphous phase by $20 \%$, facilitating nucleation and thus allowing for a denser growth of particles on fabrics. In comparison to conventional techniques (e.g., polymer surface modification ${ }^{\mathbf{4 0 , 4 2}}$ ) used to deposit MOFs on fabrics, mercerization is simpler and provides equal/higher densities of deposited MOF particles. Herein, we successfully induced the growth of MOF particles on the surface of mercerized cotton fibers (Scheme 1).

The shape and crystallinity of as-grown MOF particles were probed by scanning electron microscopy (SEM) and X-ray diffraction (XRD), while Fourier transform (FT-IR) spectroscopy was used to characterize the surface of modified cotton fabrics and confirm mercerization-induced changes. The loading of MOF particles on cotton was determined by thermogravimetric analysis (TGA), and the CWA decomposition performance of UiO-66- $\mathrm{NH}_{2}$-functionalized cotton was assessed using the TOP-08-2-501A (ref. 44) method for soman (GD) and sulfur mustard (HD) as model compounds.

\section{Experimental}

\section{Materials}

$\mathrm{ZrOCl}_{2} \cdot 8 \mathrm{H}_{2} \mathrm{O}(99.5 \%), \mathrm{N}, \mathrm{O}$-bis(trimethylsilyl)trifluoroacetamide (TMS, 99\%), ethyl acetate (EA, 99.8\%), N,N-dimethylformamide (DMF), $\mathrm{NaOH}$ pellets (98\%), and hydrochloric acid (37\%) were purchased from Sigma-Aldrich. 2-Aminoterephthalic acid (99\%) was purchased from Alfa Aesar, and anhydrous ethanol (99.5\%) was purchased from Samchun Chemical. Raw cotton fabrics were sourced from a commercial market (Nubyon). CWAs were synthesized in laboratories designated by the Organisation for the Prohibition of Chemical Weapons, and the quality of these agents was confirmed by ${ }^{1} \mathrm{H}$ NMR (e.g., purity of HD was determined to exceed 99\%). Caution! CWAs are extremely dangerous compounds that need to be handled in a fume hood by skilled researchers wearing personal protective equipment.

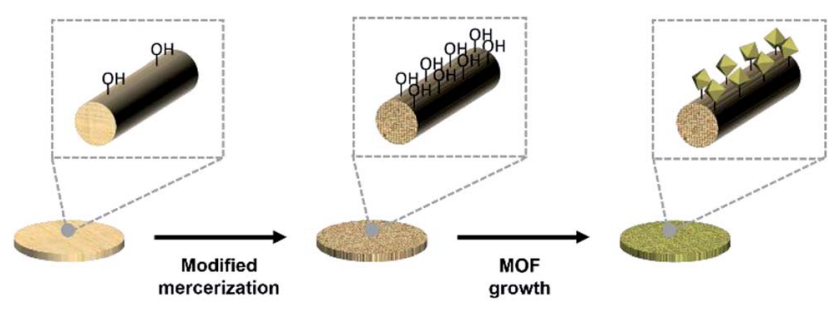

Scheme 1 Crystallization of MOFs on mercerized cotton fabric.

\section{Mercerization of cotton fabrics}

$\mathrm{NaOH}(400 \mathrm{~g})$ was dissolved in distilled water $(600 \mathrm{~mL})$ upon stirring followed by cooling to room temperature. Cotton fabric pieces $(10 \times 10 \mathrm{~cm})$ were soaked in the above solution in such a way as to prevent them from folding and not allow any air bubbles to be trapped underneath. After becoming completely wet, the samples were further incubated at room temperature for $4 \mathrm{~h}$, removed, washed in distilled water, thoroughly rinsed upon rubbing, and further washed until the $\mathrm{pH}$ of the washings became neutral. After complete neutralization, the specimens were placed into a vacuum oven and sufficiently dried at $70{ }^{\circ} \mathrm{C}$ for further use.

\section{MOF growth on mercerized cotton fabrics}

$\mathrm{ZrOCl}_{2} \cdot 8 \mathrm{H}_{2} \mathrm{O}(6.09 \mathrm{~g})$ was dissolved in a mixture of DMF (175 $\mathrm{mL}$ ) and hydrochloric acid ( $35 \mathrm{~mL}$ ) upon $20 \mathrm{~min}$ sonication. The reaction mixture was treated with 2 -aminoterephthalic acid (4.69 g) and DMF (350 mL) and sonicated for another $20 \mathrm{~min}$. Mercerized cotton fabrics were dipped directly into the thus prepared solution, and the reaction jar was placed into an oven and heated at $80{ }^{\circ} \mathrm{C}$ for $24 \mathrm{~h}$. After the reaction was complete, the fabrics were removed from the solution, soaked with DMF and sonicated for $5 \mathrm{~min}$ to eliminate residuals from fabrics. The washing process was repeated three times in DMF and then performed for another three times in ethanol to remove DMF residues. The whole procedure for MOF growth was repeated for a total of five times to increase the density of deposited MOF particles, and the obtained products were activated by $24 \mathrm{~h}$ heating in vacuum at $120{ }^{\circ} \mathrm{C}$.

\section{Material characterization}

As-synthesized UiO-66- $\mathrm{NH}_{2}$-functionalized cotton was characterized by XRD, SEM, FT-IR spectroscopy, and TGA. XRD patterns were recorded on a D8 Discover (Bruker) instrument in a $2 \theta$ range of $0-40^{\circ}$. SEM imaging was performed on a Quanta650 (FEI) instrument, and TGA (Q500, TA Instruments) was carried out by heating samples from 25 to $800^{\circ} \mathrm{C}$ at a rate of $10{ }^{\circ} \mathrm{C} \min ^{-1}$ under $\mathrm{N}_{2}$ gas.

\section{AVLAG swatch test}

The degree of CWA permeation was measured using an AVLAG (Aerosol Vapor Liquid Assessment Group) test cell, ${ }^{45}$ which is a device commonly used to measure the ability of military protective fabrics to withstand CWAs. The employed equipment comprised a temperature and humidity controller used to control the air flow rate, air temperature/humidity, and test time, a control unit used to maintain the temperature inside the chamber, and a test cell containing the investigated specimen (Scheme 2). The tested specimen was cut into small pieces with a diameter of $4.5 \mathrm{~cm}$ using a dedicated cutter, and prior to the swatch testing the cut pieces were treated in a chamber at a temperature of $32{ }^{\circ} \mathrm{C}$ and a relative humidity of $80 \%$ for $\geq 2 \mathrm{~h}$ so that samples were kept to the same condition to the test. The specimen to be tested was mounted onto the test cell fixture and covered by the selected agent $(4 \times 1 \mu \mathrm{L}$ drops of HD or $5 \times 1 \mu \mathrm{L}$ 


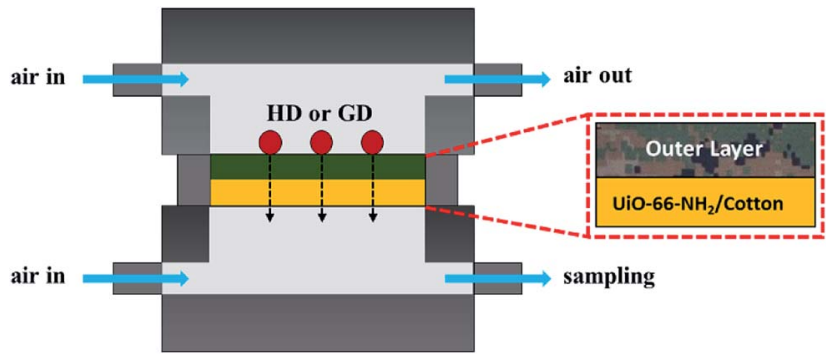

Scheme 2 AVLAG swatch test used to determine CWA permeation levels.

drops of GD) using a syringe. The cell containing the agentsoaked specimen was assembled and mounted inside the experimental chamber. Air was fed to the upper $\left(0.25 \mathrm{~L} \mathrm{~min}^{-1}\right)$ and lower $\left(0.3 \mathrm{~L} \mathrm{~min}^{-1}\right)$ block inlets of the test cell and was discharged from the upper block outlet of the experimental chamber, causing the agent challenge in a liquid form to evaporate over time as would happen in the field. Air discharged from the lower block outlet was collected using an adsorption tube (adsorbent $=$ Tenax for HD, Porapak Q for GD) and desorbed using a thermal desorption instrument (Turbo Matrix 650 , Perkin-Elmer). The content of permeated CWA in desorbed air was analyzed by gas chromatography (Agilent, GC7890B/ 5977A MSD).

\section{Decomposition of CWAs}

After the swatch test, CWA decomposition products were treated with TMS and analyzed by gas chromatography-mass spectrometry (GC-MS) ${ }^{47,48}$ The commonly employed procedure was slightly modified to fit the needs of large-size specimen analysis. After the swatch test was complete, the specimen was collected, placed into a $125 \mathrm{~mL}$ glass bottle, and extracted with EA $(30 \mathrm{~mL})$ for $2 \mathrm{~h}$. The extract was filtered, and a $200 \mu \mathrm{L}$ aliquot was transferred into a $1 \mathrm{~mL}$ vial and treated with a solution of TMS $(200 \mu \mathrm{L})$. The reaction was allowed to proceed for $2 \mathrm{~h}$ at $60^{\circ} \mathrm{C}$, and $1 \mu \mathrm{L}$ of the reaction mixture was injected into the GCMS instrument. The injection port was maintained at $250{ }^{\circ} \mathrm{C}$, and the GC-MS oven temperature was raised from 45 to $230^{\circ} \mathrm{C}$ at a rate of $10{ }^{\circ} \mathrm{C} \mathrm{min}^{-1}$. The mass spectrometer used for analysis was operated in electron ionization mode, and scanning was performed in the range of $m / z=30-550$ at a rate of 2.8 scans per s.

\section{Results and discussion}

\section{Material characterization}

SEM imaging revealed that mercerization did not result in changes of cotton surface morphology and facilitated the formation of particle nucleation points, i.e., the modified fibers were covered by well-grown MOF particles. Fig. 1 shows that particle growth on the cotton fabric resulted in a color change from essentially colorless to dark yellow, while the original texture and flexibility were retained.

Notably, no MOF particles could be removed from the dried specimens, since all weakly held particles in these specimens
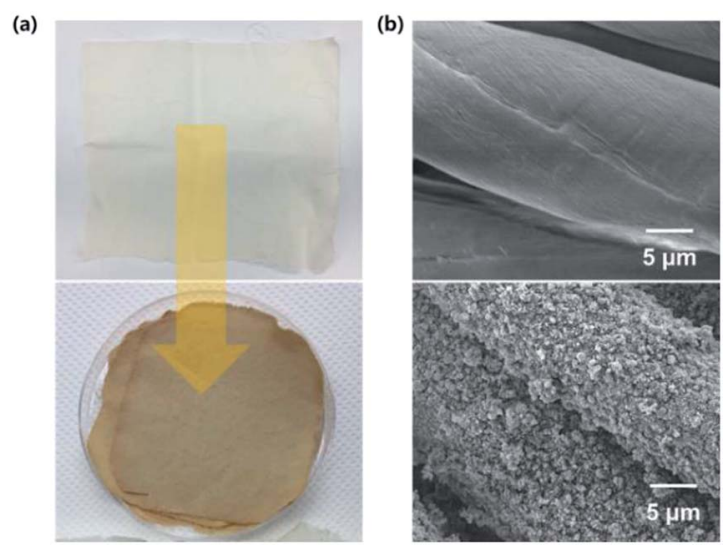

Fig. 1 Photographic (a) and SEM (b) images of pristine and UiO-66$\mathrm{NH}_{2}$-functionalized cotton fabrics.

had already been removed during $30 \mathrm{~min}$ ultrasonication. Fig. 1(b) shows the surface morphology of MOF-coated cotton, revealing that UiO-66- $\mathrm{NH}_{2}$ particles were uniformly and densely dispersed on the fabric. Thus, in contrast to conventional techniques requiring complicated fiber modification procedures or the use of techniques such as ALD, ${ }^{37-40}$ we could grow dense, continuous, and uniform layers of MOF particles (thickness assumed $\approx 600 \mathrm{~nm}$ ) on the surface of the cotton fabric in a relatively easy manner (Fig. S1 $\dagger$ ).

Fig. 2 shows the XRD patterns of pristine and UiO-66- $\mathrm{NH}_{2}-$ functionalized cotton fabrics and UiO-66- $\mathrm{NH}_{2}$ itself, revealing that the pattern of UiO-66- $\mathrm{NH}_{2}$ is dominated by reflections from the (111) and (222) planes of UiO-66, ${ }^{49}$ in good agreement with the results of previous studies. ${ }^{45}$ The particles of UiO-66- $\mathrm{NH}_{2}$ grown on the fiber surface exhibited excellent crystallinity, which implied that (i) the above surface was well suited for MOF crystallization and (ii) the mercerized cotton did not significantly interfere with particle crystallization. The distribution of crystallite sizes was approximately $60-100 \mathrm{~nm}$ in average in the final composite fabric.

Fig. 3 shows the FT-IR spectra of natural and mercerized cotton. Peaks in the range of $3600-2995 \mathrm{~cm}^{-1}$ were ascribed to

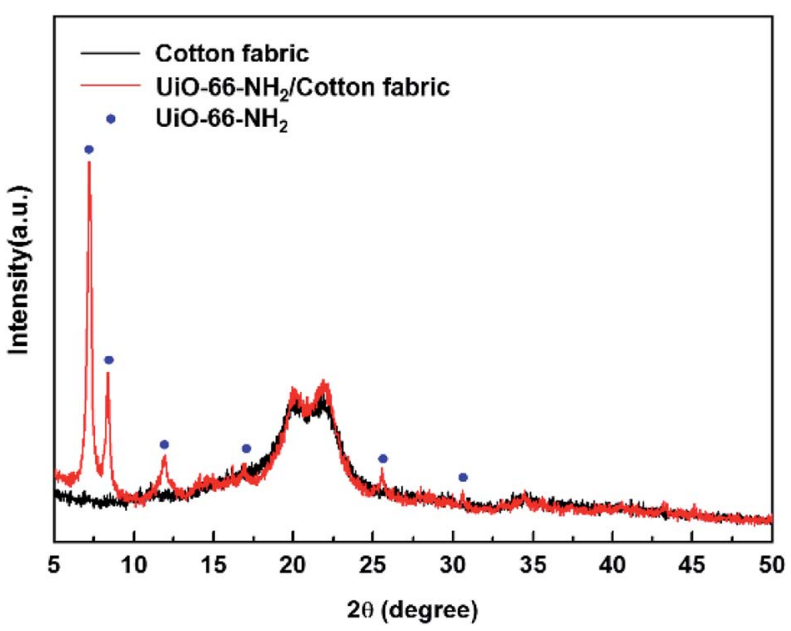

Fig. 2 XRD patterns of pristine and $\mathrm{UiO}-66-\mathrm{NH}_{2}$-functionalized cotton fabrics and $\mathrm{UiO}-66-\mathrm{NH}_{2}$ particles. (Blue points: reference of UiO-66- $\mathrm{NH}_{2}$ (ref. 45)). 


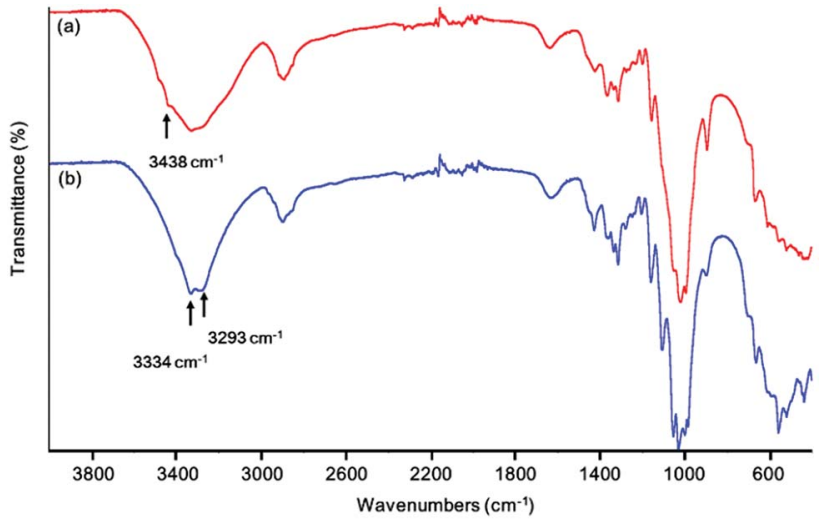

Fig. 3 FT-IR spectra of (a) mercerized and (b) pristine cotton.

the stretching vibrations of hydrogen-bonded $\mathrm{OH}$ groups, and relative intensity variations observed for signals at 3438, 3334, and $3293 \mathrm{~cm}^{-1}$ were related to changes in the crystal structure of hydroxyl groups caused by the transformations of cellulose in the alkaline medium. ${ }^{50}$ The IR result of cotton treated with alkaline solution are consistent with reported data. ${ }^{50}$ Moreover, the acquired data show that the number of free hydroxyl groups on the surface of cellulose increased upon its conversion into an amorphous state upon base treatment, which was expected to facilitate MOF particle growth.

In contrast to most MOFs, which exhibit the disadvantages of poor thermal stability and sensitivity to moisture, ${ }^{51} \mathrm{Zr}-\mathrm{MOFs}$ are known to feature excellent thermal stability and moisture sensitivity. ${ }^{52,53}$ Fig. 4 shows the TGA curves of MOF-coated/ pristine cotton and UiO-66- $\mathrm{NH}_{2}$. The curve of pure UiO-66$\mathrm{NH}_{2}$ powder (Fig. 4(a)) featured a mass decrease at $\sim 100{ }^{\circ} \mathrm{C}$ caused by the loss of $\mathrm{H}_{2} \mathrm{O}$ adsorbed in pores, and the subsequent rapid mass loss at $\sim 400^{\circ} \mathrm{C}$ reflected the decomposition of organic moieties, while nearly no further mass loss was observed up to $1000{ }^{\circ} \mathrm{C}$. Fig. 4(b) shows the TGA curve of MOFfunctionalized cotton, revealing that the rapid mass loss at approximately $400{ }^{\circ} \mathrm{C}$ corresponded to an almost complete removal of the cotton matrix and demonstrating that this mass loss was almost equal to that observed for pristine cotton

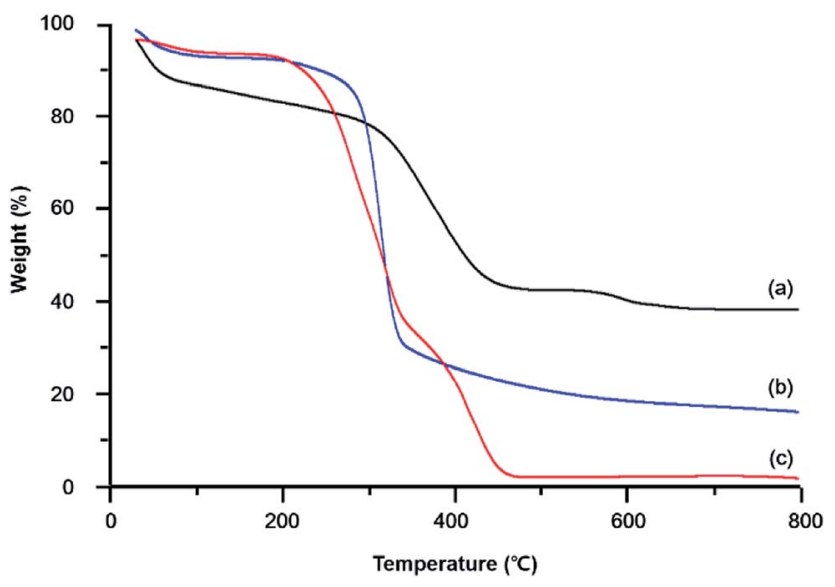

Fig. 4 TGA curves of (a) UiO-66- $\mathrm{NH}_{2}$ powder, (b) $\mathrm{UiO}-66-\mathrm{NH}_{2}-$ functionalized cotton, and (c) pristine cotton.
(Fig. 4(c)). The mass loss above $500{ }^{\circ} \mathrm{C}$, estimated as $\sim 20 \%$, was ascribed to the decomposition of UiO-66- $\mathrm{NH}_{2}$ to afford $\mathrm{ZrO}_{2}$. Based on the data in Fig. 4(a) and (b), the loading of UiO- $66-\mathrm{NH}_{2}$ was estimated as $\sim 51 \mathrm{wt} \%$.

\section{Protective performance of UiO-66- $\mathrm{NH}_{2}$-functionalized cotton fabrics}

MOFs can not only adsorb chemical agents but also decompose them into non-toxic materials via hydrolysis. Although activated carbon is commonly used to adsorb chemical agents, Zr-based MOFs possess increased active sites on the porosity of the framework, as probed by $\mathrm{N}_{2}$ adsorption. ${ }^{36}$ MOFs are also known to rapidly degrade nerve agents such as GD, VX, and their analogues. ${ }^{54,55}$ Additionally, a large number of studies focus on the degradation of such agents in buffer solutions with $\mathrm{pH}$ 8-10 and thus contribute to a deeper understanding of the corresponding mechanism. However, the ability of MOF-modified fabrics to withstand CWA permeation has been relatively underexplored. Therefore, we herein evaluated the CWA permeation performance of MOF-modified fabrics ${ }^{44}$ with the obtained results listed in Table 1. Table 1 reveals that compared to those observed for pristine cotton, the HD and GD permeabilities of MOF-impregnated cotton were lower by factors of $\sim 10$ and 20, respectively, which indicated that the above CWAs were effectively removed by porous MOF particles. Moreover, the results of numerous studies suggest that the adsorption of CWAs is accompanied by their hydrolysis.

The degradation of CWAs promoted by Zr-based hydroxides and Zr-MOFs has been extensively studied. ${ }^{12,14}$ Importantly, amine-functionalized UiO-66- $\mathrm{NH}_{2}$ was shown to hydrolyze dimethyl methylphosphate, a simulant, more rapidly than UiO66 and other Zr-based MOFs ${ }^{56}$ Herein, extraction experiments were performed to confirm CWA degradation by UiO-66- $\mathrm{NH}_{2}{ }^{-}$ functionalized cotton after the swatch test.

As a result, the stepwise hydrolysis of GD was shown to initially afford pinacolyl methylphosphonic acid (PMPA), which was subsequently further hydrolyzed to methylphosphonic acid (MPA) (Fig. 5(a)). Upon TMS treatment, the $\mathrm{H}$ atom of the hydroxyl group was replaced with the TMS $\left(\mathrm{Me}_{3} \mathrm{Si}\right)$ group, which facilitated GC analysis. ${ }^{46}$ Fig. 5(b) and (c) show GC and MS data acquired for the final GD extract, respectively. Notably, whereas this CWA was degraded to non-toxic MPA over MOFimpregnated cotton, no MPA was detected in the extract obtained for raw cotton (Fig. S2 $\dagger$ ). In most previous studies on simulants or CWAs themselves, analysis was performed at constant $\mathrm{pH}$ to ensure high analysis speed and effective performance determination. However, to obtain results

Table 1 Permeation of selected CWAs (HD, GD) through MOFmodified and pristine cotton fabrics

\begin{tabular}{lll}
\hline Agent & Specimen & Permeation $\left(\mu \mathrm{g} \mathrm{cm}^{-2}\right)$ \\
\hline \multirow{2}{*}{$\mathrm{HD}$} & UiO-66- $\mathrm{NH}_{2} /$ cotton & 16 \\
& Cotton & 184 \\
GD & UiO-66- $\mathrm{NH}_{2} /$ cotton & 5 \\
& Cotton & 120
\end{tabular}


(a)

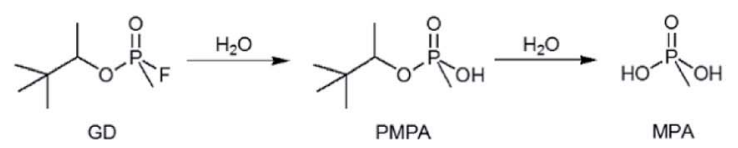

(b)

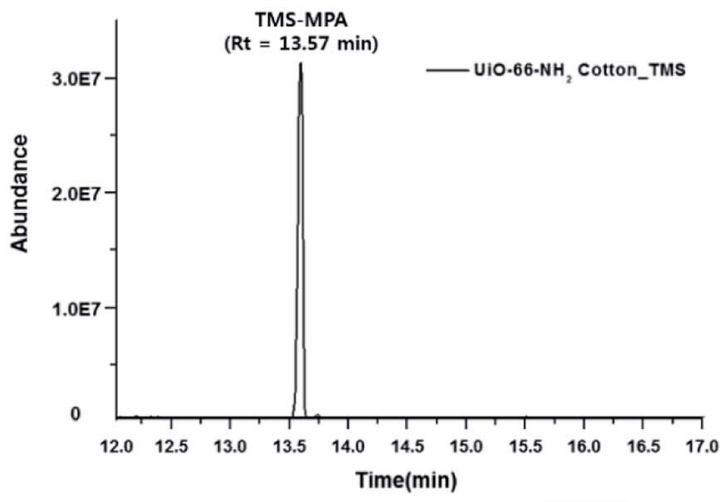

(c)

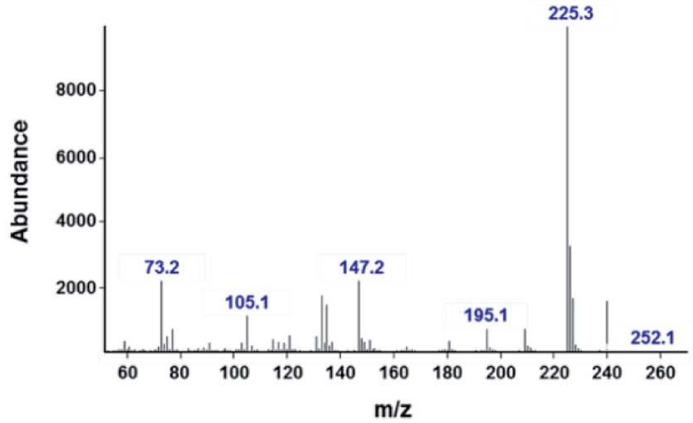

Fig. 5 (a) GD hydrolysis pathway; (b) GC spectrum and (c) MS spectrum of the extract obtained for in the $\mathrm{GD} / \mathrm{UiO}-66-\mathrm{NH}_{2}$-functionalized cotton fabric system.

accurately representing the performances of protective gear or cloth, it is crucial to investigate direct CWA permeation and the corresponding degradation. To the best of our knowledge, this work is the first one to describe GD and HD (Fig. S3†) vapor adsorption/degradation during permeation through a cotton fabric.

\section{Conclusions}

This study describes a technique that allows one to easily grow MOFs on mercerized cellulose-based fabrics, revealing that mercerization in a basic aqueous solution results in the insertion of $\mathrm{Na}^{+}$ions between the hydroxyl groups of cellulose to induce fiber surface flattening and thus facilitates the insertion of dye-like substances between cellulose chains. Moreover, the above treatment increases the accessibility of fibers to MOF precursors, and the increased number of free hydroxyl groups results in an elevated quantity of nucleation points, thereby enabling dense MOF coating. The CWA protection performance of the MOF-coated fabric was assessed using the swatch test, and the above fabric was shown to effectively degrade both GD and HD and was concluded to be well suited for the adsorption and degradation of CWAs.

\section{Conflicts of interest}

There are no conflicts to declare.

\section{Acknowledgements}

The authors thank the Chemical Analysis Test and Research Lab for providing GD and HD and express their gratitude to Dr Baek and Ms. Kim for assistance with XRD and SEM analyses. This research was supported by the Agency for Defense Development research project (Grant No. 912412201).

\section{Notes and references}

1 L. Szinicz, Toxicology, 2005, 215, 167.

2 Y. C. Yang, J. A. Baker and J. R. Ward, Chem. Rev., 1992, 92, 1729.

3 F. R. Sidell and J. Borak, Ann. Emerg. Med., 1992, 21(7), 865. 4 P. Lodewyckx and T. J. Bandosz, Activated Carbon Surfaces in Environmental Remediation, Elsevier LTD., Oxford, 2006.

5 I. Columbus, D. Waysbort, L. Shmueli, I. Nir and D. Kaplan, Environ. Sci. Technol., 2006, 40, 3952.

6 D. Kaplan, L. Shmueli, I. Nir, D. Waysbort and I. Columbus, Clean: Soil, Air, Water, 2007, 35, 172.

7 I. Candel, M. D. Marcos, R. Martinez-Manez, F. Sancenon, A. M. Costero, M. Parra, S. Gil, C. Guillem, F. Perez-Pla and P. Amoros, Microporous Mesoporous Mater., 2015, 217, 30.

8 S. Dadvar, H. Tavanai, M. Morshed and M. Ghiaci, J. Chem. Eng. Data, 2012, 57, 1456.

9 H. Jung, H. W. Lee and E. A. Jung, Phosphorus, Sulfur Silicon Relat. Elem., 2016, 191, 1137.

10 G. W. Peterson, G. W. Wagner, J. H. Keller and J. A. Rossin, Ind. Eng. Chem. Res., 2010, 49, 11182.

11 T. J. Bandosz, M. Laskoski, J. Mahle, G. Mogilevsky, G. W. Peterson, J. A. Rossin and G. W. Wagner, J. Phys. Chem. C, 2012, 116, 11606.

12 G. W. Peterson, C. J. Karwacki, W. B. Feaver and J. A. Rossin, Ind. Eng. Chem. Res., 2009, 48, 1694.

13 R. B. Balow, J. G. Lundin, G. C. Daniels, W. O. Gordon, M. McEntee, G. W. Peterson, J. H. Wynne and P. E. Pehrsson, ACS Appl. Mater. Interfaces, 2019, 9, 39747.

14 M. Seredych and T. Bandosz, Chem. Eng. J., 2011, 166, 1032. 15 M. Seredych and T. Bandosz, J. Phys. Chem. C, 2010, 114, 14552.

16 G. W. Wagner and P. W. Bartram, Langmuir, 1999, 15, 8113. 17 S. L. Giles, J. G. Jundin, R. B. Balow, P. E. Pehrsson and J. H. Wynne, Appl. Catal., 2017, 542, 306.

18 R. P. Johnson and C. L. Hill, J. Appl. Toxicol., 1999, 19, S71. 19 D. M. Mizrahi, S. Sphier and I. Columbus, J. Hazard. Mater., 2010, 179, 495.

20 J. B. DeCoste and G. W. Peterson, Chem. Rev., 2014, 114, 5695.

21 Y. Liu, S.-Y. Moon, J. T. Hupp and O. K. Farha, ACS Nano, 2015, 9, 12358.

22 J. E. Mondloch, M. J. Katz, W. C. Isley, P. Ghosh, P. Liao, W. Bury, G. W. Wagner, M. G. Hall, J. B. DeCoste, 
G. W. Peterson, R. Q. Snurr, C. J. Cramer, J. T. Hupp and O. K. Farha, Nat. Mater., 2015, 14, 512.

23 S. Y. Moon, Y. Liu, J. T. Hupp and O. K. Farha, Angew. Chem., Int. Ed., 2015, 54, 6795.

24 A. Roy, A. K. Srivastava, B. Singh, T. Mahato, D. Shah and A. Halve, Microporous Mesoporous Mater., 2012, 162, 207.

25 H. Furukawa, K. E. Cordova, M. O'Keeffe and O. M. Yaghi, Science, 2013, 341, 1230444.

26 D. J. Tranchemontagne, J. L. Mendoza-Cortés, M. O'Keeffe and O. M. Yaghi, Chem. Soc. Rev., 2009, 38, 1257.

27 M. Li, D. Li, M. O'Keeffe and O. M. Yaghi, Chem. Rev., 2014, 114, 1343.

28 E. Barea, C. Montoro and J. A. Navarro, Chem. Soc. Rev., 2014, 43, 5419.

29 J. Zhao, W. T. Nunn, P. C. Lemaire, Y. Lin, M. D. Dickey, C. J. Oldham, H. J. Walls, G. W. Peterson, M. D. Losego and G. N. Parsons, J. Am. Chem. Soc., 2014, 43, 5419.

30 S. Shimomura, M. Higuchi, R. Matsuda, K. Yoneda, Y. Hikata, Y. Kubota, Y. Mita, J. Kim, M. Takata and S. Kitagawa, Nat. Chem., 2010, 2, 633.

31 J. Lee, O. K. Farha, J. Roberts, K. A. Scheidt, S. T. Nguyen and J. T. Hupp, Chem. Soc. Rev., 2009, 38, 1450.

32 Y. Zhang, S. Yuan, X. Feng, H. Li, J. Zhou and B. Wang, J. Am. Chem. Soc., 2016, 138, 5785.

33 M. C. de Koning, M. van Grol and T. Breijaert, Inorg. Chem., 2017, 56, 11804.

34 R. G. Milan, E. López-Maya, M. Hall, N. M. Padial, G. W. Peterson, J. B. DeCoste, L. M. Rodriguez-Albelo, J. E. Oltra, E. Barea and J. A. R. Navarro, ACS Appl. Mater. Interfaces, 2017, 9, 23967.

35 M. J. Katz, J. E. Mondloch, R. K. Totten, J. K. Park, S. T. Nguyen, O. K. Farha and J. T. Hupp, Angew. Chem., Int. Ed., 2014, 53, 497.

36 S. G. Ryu, M. K. Kim, M. K. Park, S. O. Jang, S. H. Kim and H. S. Jung, Microporous Mesoporous Mater., 2019, 274, 9.

37 J. Zhao, M. D. Losego, P. C. Lemaire, P. S. Williams, B. Gong, S. E. Atanasov, T. M. Blevins, C. J. Oldham, H. J. Walls, S. D. Shepherd, M. A. Browe, G. W. Peterson and G. N. Parsons, Adv. Mater. Interfaces, 2014, 1, 1400040.

38 A. X. Ju, M. McEntee, M. A. Browe, M. G. Hall, J. B. DeCoste and G. W. Peterson, ACS Appl. Mater. Interfaces, 2017, 9, 13632 .
39 M. Schelling, M. Kim, E. Otal and J. Hinestroza, Bioengineering, 2018, 5, 14.

40 J. Zhao, D. T. Lee, R. W. Yaga, M. G. Hall, H. F. Barton, I. R. Woodward, C. J. Oldham, H. J. Walls, G. W. Peterson and G. N. Parsons, Angew. Chem., Int. Ed., 2016, 55, 13224.

41 A. Centrone, Y. Yang, S. Speakman, L. Bromnerg, G. C. Rutledge and T. A. Hatton, J. Am. Chem. Soc., 2010, 132, 15687.

42 S. A. Ovalle-Serrano, V. S. Carrillo, C. Blanco-Tirado, J. P. Hinestroza and M. Y. Combariza, Cellulose, 2015, 22, 1841.

43 S. R. Karmakar, Text. Sci. Technol., 1999, 12, 289.

44 Individual protection capability area process action team (CAPAT), Test Operations Procedures (TOP) 08-2-501A.

45 M. Kandiah, M. H. Nilsen, S. Usseglio, S. Jakobsen, U. Olsbye, M. Tilset, C. Karabi, E. A. Quadrelli, F. Bonino and K. P. Lillerud, Chem. Mater., 2010, 22, 6632.

46 D. '. Onofrio and G. Terrence, ECBC-TR-114, US Army Research, Development and Engineering Command, 2013.

47 T. Yokota, K. Kiraga, H. Yamane and N. Takai-Iashi, Phytochemistry, 1975, 14, 1569.

48 H. Jung and K. C. Lim, Environ. Chem. Lett., 2016, $14,367$.

49 P. Kanoo, K. L. Gurunatha and T. K. Maji, J. Mater. Chem., 2010, 20, 1322.

50 Y. Yue, G. Han and Q. Wu, BioResources, 2013, 8, 6460.

51 S. B. Kalidindi, S. Nayak, M. E. Briggs, S. Jansat, A. P. Katsoulidis, G. J. Miller, J. E. Warren, D. Antypov, F. Cora, B. Slater, M. R. Prestly, C. Martí-Gastaldo and M. J. Rosseinsky, Angew. Chem., Int. Ed., 2015, 54, 221.

52 J. H. Cavka, S. Jakobsen, U. Olsbye, N. Guillou, C. Lamberti, S. Bordiga and K. P. Lillerud, J. Am. Chem. Soc., 2008, 130, 13850.

53 H. Furukawa, F. Gándara, Y. Zhang, J. Jiang, W. L. Queen, M. R. Hudson and O. M. Yaghi, J. Am. Chem. Soc., 2014, 136, 4369.

54 N. S. Bobbitt, M. L. Mendonca, A. J. Howarth, T. Islamoglu, J. T. Hupp, O. K. Farha and R. Q. Snurr, Chem. Soc. Rev., 2017, 46, 3357.

55 Y. Y. Liu, A. J. Howarth, N. A. Vermeulen, S. Y. Moon, J. T. Hupp and O. K. Farha, Coord. Chem. Rev., 2017, 346, 101.

56 M. J. Katz, S.-Y. Moon, J. E. Mondloch, M. H. Beyzavi, C. J. Stephenson, J. T. Hupp and O. K. Farha, Chem. Sci., 2015, 6, 2286. 